\title{
The Effect of Brain-Compatible Strategies on Problem Solving Performance of Grade 4 and 5 Lebanese Students
}

\author{
Rola Shukry-Balaa (MA, Educational Psychology) \\ Karma El-Hassan (PhD, Educational Psychology) \\ American University of Beirut, Lebanon
}

Doi:10.19044/esj.2018.v14n19p149 URL:http://dx.doi.org/10.19044/esj.2018.v14n19p149

\begin{abstract}
This study investigated the effect of training in Prior Knowledge Activation, Concept Mapping, and Think Aloud, on students' problem solving performance. The relative effectiveness of the training among high and low achievers was also examined. Participants were 45 students in Grades 4 and 5 in two private schools in Lebanon (25 students experimental group; 20 as control). The experimental group received 3 weeks training, in addition to the regular methods while the control received the regular methods only. Curriculum-based assessments (reading comprehension and math word problem solving) and Raven's Colored Progressive Matrices, were used to measure problem solving performance. ANCOVA results showed a significant difference in experimental and control groups' posttest scores, in favor of the experimental group. ANOVA results showed that the mean differences between pre and post test scores of low and high achieving students in the experimental group differed significantly only on math word problem solving measure, in favor of the low achievers. Results are discussed and implications and future recommendations are presented.
\end{abstract}

Keywords: Problem Solving, Activating Prior Knowledge, Concept Mapping, Think Aloud

\section{Introduction}

One of the ultimate goals of education is preparing learners to become real-life problem solvers. Extensive research has been conducted to verify the effect of certain strategies on learners' performance on problem solving tasks, especially content related tasks (McCormick, Miller, \& Pressley, 1989; Montague, Krawec, Enders, \& Dietz, 2014; Pressley \& Harris, 2008; Swanson \& Hoskyn, 1998; Wong, Harris, Graham, \& Butler, 2003). Yet, teachers report that learners find difficulty in solving real life problems. Phye (2001) 
points out that there remains a distinction between acquisition of skills during instruction and later problem solving. The search for effective tools which could help in improving the problem solving performance of learners is more pronounced, especially that inclusive education is prevailing now in today's schools. Special learners have been found to have few metacognitive strategies for monitoring their learning and for dealing with problems (Wilder \& Williams, 2001). Low achieving learners have gaps in skills and require support. Inclusive classroom teachers are therefore in need of tools that can improve the problem solving performance among their diverse student population.

Brain-based learning is an approach that incorporates 12 principles which are derived from a synthesis of research-based information on how the brain works and on learning (Fogarty, 2009). The approach is described as engaging strategies that are governed by principles related to the understanding of how the brain functions (Jensen, 2008). The association of brain research and learning is meant to help maximize the brain's natural learning processes and achieve meaningful lifelong learning (Caine \& Caine, 1995). According to this approach, strategies which are based on the science of how the brain works are expected to improve learners' problem solving performance.

This study addressed three brain compatible strategies namely, Prior Knowledge Activation (PKA), Concept Mapping (CM), and Think Aloud (TA). PKA, CM, and TA are considered brain compatible since they are claimed to work consistently with how the brain works (Jensen, 1998; Jensen \& Dabney, 2001; Wolfe, 2001). To ensure the development of successful problem solvers, one needs to act at the level of problem classification, problem representation, and flexible, effective solution generation. Brainbased learning recommends embedding problems into a meaningful context so that problem solvers have a real and clear classification of the problem. Activating students' prior knowledge can best serve this purpose for it stimulates the context of what the learner already knows so that assimilation of new information is enhanced. To aid in problem representation, visual representational tools are advocated by brain-based learning. Concept maps can act as visual cues highlighting various aspects of a given problem and engaging less cognitive load. As for effective and flexible solution generation, this can be guided by having individuals think aloud the different cognitive processes they can undertake as they generate solutions. Thinking aloud may be treated as a form of self-monitoring as students verbalize the probable solutions; thus having a higher chance of self-evaluating the effectiveness of the generated solutions.

Although there is an interest in brain-based education, it has received criticism, in terms of producing unequivocal conclusions (Sternberg, 2008). 
Questions as to whether the outcomes of brain research do have any direct application to educational practices were also raised (Abbeduto, 2004), as minimal controlled research on the impact of brain-based learning strategy implementation in the classroom existed (Winters, 2001). Nevertheless, the approach has evolved (Jensen, 2008). Studies addressing brain-based learning and student attitudes, science, social studies, and physical education, academic achievement and retention, multiple intelligences, and reading comprehension have emerged (e.g. Bello, 2007; Brodnax, 2004; Duman, 2010; Haghighi, 2013; Suarsana, Widiasih, \& Suparta, 2017; Tüfekçia \& Demirel, 2009; Youness \& AbdelFattah, 2015). Yet, efforts to study the effectiveness of brain compatible strategy instruction on the problem solving performance of learners are fairly scant.

In Lebanon, very few studies have tackled problem solving. El Daw (1997) investigated the effect of training in language related concepts and selfinstruction on self-regulated problem solving of children with mild intellectual problems. Other studies, focused on social problem solving (e.g. El-Hassan \& Moughanie, 2014; Nashabi, 1998). The scarcity of research on problem solving performance of Lebanese students reveals a need for relevant research.

The purpose of this study was to (1) examine the effect of training in three brain-compatible strategies (PKA, CM, and TA) on the problem solving performance within academic content areas, namely reading comprehension and mathematical word problem solving, and on content free problem solving tasks, and (2) determine whether the three strategies will have different effects on the problem solving performance of high and low achieving students.

\section{Method}

The sample. Participants in this study were 45 students in Grades 4 and 5 in two upper middle class, privately owned schools located in suburban Lebanon. Two intact classes (Grades 4 \& 5) were selected from each school. One school was used for the experimental condition and the other as the control. A total number of 20 students were in the control group while 25 students were in the experimental group. Both schools are sister schools that have the same management, adopt the same educational philosophy, and both implement the same curricula (MacMillan / McGraw-Hill English and Math curricula).

Tools. Problem solving performance within academic content and on content free problem solving tasks was assessed pre and post training using curriculum-based assessments and using Raven Colored Progressive matrices.

Reading comprehension and math tests. To measure problem solving performance within academic content, reading comprehension and math word problem solving pretest and post tests were developed. Reading comprehension pretest was selected from the tests that are provided by 
MacMillan/McGraw-Hill curriculum. It consisted of a reading passage and a set of comprehension questions. Reading comprehension posttest was also selected from the MacMillan/McGraw-Hill curriculum. It consisted of another reading passage with its set of comprehension questions. Both pre and posttests assessed the same set of comprehension skills. For the math tests, a pretest included selected items from the assessments that are provided at the end of every chapter in MacMillan/McGraw-Hill math curriculum. Items included exercises that target math word problem solving. As for the math post-test, it was assembled following the same procedure as that for the pretest but exercises were selected from Form B (equivalent form) of the assessment tests provided by the curriculum.

Colored Progressive Matrices (CPM). Content free problem solving performance was assessed through Raven's Progressive Matrices. The Colored Progressive Matrices (CPM) was the form adopted for this study since it suits the age range of the participants and its administration requires minimal verbal instruction. The 36-item test was administered as a group test and no feedback to students about their performance was provided after pretest.

Design and procedure. The study followed a pretest-posttest control group design. Following a preparatory phase, the study was conducted over three phases: a pretest, a training, and a post testing phase. All participants were administered the pretests. The experimental group received training in using PKA, TA, and CM while the control did not receive such training and continued to receive the regular schedule. Following implementation of the training, all participants were administered post-tests.

Preparatory phase. The investigator clarified to Grade 4 and 5 homeroom teachers in both schools that, during the training period, both groups should be receiving the same academic content in Math and in English. Therefore, it was necessary for the investigator to check both, experimental and control groups' lesson plans. Homeroom teachers were also provided a training to administer CPM, following the procedure in Raven Progressive Matrices Manual. As for the reading comprehension and math tests, the regular procedures when testing students were to be followed. Finally the subjects' scores for the first trimester of the academic year were collected. A cutoff score of 60/100 was used to determine high and low achieving groups. All students whose average score on the required Grade 4 and Grade 5 tests in Reading comprehension and Mathematics was below the cutoff were treated as low achieving group. In the experimental group, 10 students were determined as low achievers while 15 were considered as high achievers. As for the control group, 9 were low achievers while 11 were high achievers.

Phase I: Pretest. All 45 subjects were administered reading comprehension and math curriculum-based assessment pretests as well as CPM by their homeroom teachers. 
Phase II: Training. Strategy instruction training was given to 25 students in the experimental group (Grades 4 and 5) on 9 weekly sessions, for 3 weeks. Each session lasted 30 minutes. Training was conducted in the presence of homeroom teachers. After a total of 27 training sessions, one 50 minutes session was dedicated for evaluation. During the training, the experimental group received explicit instruction in using PKA, CM, and TA, with one strategy being introduced and practiced systematically for a week. Training involved a) clear definition and presentation of the strategy highlighting how it helps in solving problems, modeling the use of the strategy when answering reading comprehension questions and solving math word problem tasks, and prompting students as needed while they applied the strategy to similar tasks during 2 whole group based activities; b) providing guided practice opportunities to use each strategy with corrective feedback for a minimum of 3 reading comprehension and 3 math word problem solving tasks that were completed on individual basis; and c) independent practice whereby the trainer observed students as they applied each strategy independently, followed by feedback at the completion of the work. Throughout the training period, the trainer documented qualitative remarks pertaining to students' attitudes and behaviors during the sessions, need for reteaching, or changes in teaching methods, such as integrating peer-correction as it proved to be motivating. In addition to the training, the experimental group continued to receive the preset academic plans by their homeroom teachers using regular teaching methods.

Students in the control group received the regular teaching methods that combine elements of lecture, discussion, small group work, and independent practice, with hands-on experiences and computer assisted instruction, as the regular methods used by homeroom teachers of the experimental group.

Phase III: Post testing. After 3 weeks of training, all 45 subjects were administered reading comprehension and math curriculum-based assessment post-tests as well as CPM by their homeroom teachers.

Training content. Free of culture bias stories were chosen from SRA Reading Laboratory to be used as medium to deliver training in strategy use. SRA Reading Laboratory provides interesting and relatively short stories (1-2 pages) that are designed for independent reading. Selections that lend to the application of the PKA, CM, and TA were chosen for group, guided, and independent based activities. From MacMillan / MacGraw-Hill math curriculum, math word problem solving tasks which presented real life situations were also chosen. Adaptations were however applied in order to render the tasks more resembling situations that Lebanese children encounter. All math tasks were given to two experts in the field to ensure that they target math word problem solving skills for Grades 4 and 5 students. 
Data analysis. ANCOVA was conducted to investigate any significant differences between posttest scores of the experimental and the control group on reading comprehension, math word problem solving, and content free problem solving tasks. Pretest scores of the experimental and control group on the three measures were used as covariates to control for initial difference between the two groups. ANOVA was used to investigate significant differences in the computed mean difference between pretest and posttest scores on the three measures for low and high achievers within the experimental group.

\section{Results}

Academic problem solving tasks. ANCOVA results showed a significant difference in post-test scores on reading comprehension, in favor of the experimental group. Although the covariate pretest score on reading comprehension accounts for a portion of the total variation in the posttest score (0.36), there was a main significant effect for treatment. Students exposed to training in PKA, CM, and TA $(M=79.2)$ scored significantly higher on reading comprehension posttests than those not exposed to this instruction $(\mathrm{M}=58.5)$, $\mathrm{F}(1,42)=5.36, \mathrm{p}<0.05$. ANCOVA showed similar results for math problem solving, as a significant difference in post test scores was shown in favor of the experimental group. Although the covariate pretest score on math word problem solving accounts for a portion of the total variation in the posttest score (0.49), there is a significant increase in the experimental groups' posttest scores. Students exposed to training in PKA, CM, and TA $(M=62.9)$ scored significantly higher on math word problem solving posttests than those not exposed to this instruction $(\mathrm{M}=40.9), \mathrm{F}(1,42)=8.58, \mathrm{p}<0.005$. Table 1 reports degrees of freedom, means squared, $\mathrm{F}$ ratios, and effect size measures for posttest scores of the experimental and control groups on reading comprehension questions and math word problem solving, with pretest scores as covariates.

\section{Table 1 Results of ANCOVA, with pretest measures as covariates}

\begin{tabular}{lllll}
\hline Source & $d f$ & $M S$ & $F$ & Partial Eta Squared \\
\hline Reading Comprehension & & & & \\
$\quad$ Pretest & 1 & 5772.82 & $24.09^{* *}$ & 0.36 \\
$\quad$ Treatment & 1 & 1284.46 & $5.36^{*}$ & 0.11 \\
$\quad$ Error & 42 & 239.67 & & \\
Math word problems & & & & \\
$\quad$ Pretest & 1 & 10343.49 & $40.11^{* *}$ & 0.49 \\
$\quad$ Treatment & 1 & 2213.49 & $8.58^{*}$ & 0.17 \\
$\quad$ Error & 42 & 257.76 & & \\
CPM & 1 & 9026.08 & $380.79^{* *}$ & 0.90 \\
Pretest & 1 & 98.45 & $4.15^{*}$ & 0.09 \\
$\quad$ Treatment & 42 & 23.70 & \\
$\quad$ Error & \multicolumn{5}{c}{$* \mathrm{p}<0.05, * * \mathrm{p}<0.001$} &
\end{tabular}


Colored Progressive Matrices. ANCOVA results, comparing experimental and control groups' posttest mean scores on colored progressive matrices where pretest mean scores on progressive colored matrices were used as covariates, showed a significant difference in favor of the experimental group. Students exposed to training in PKA, CM, and TA $(M=84.7)$ scored significantly higher on the colored progressive matrices than those not exposed to this instruction $(\mathrm{M}=82.5), \mathrm{F}(1,42)=4.15, \mathrm{p}<0.05$. Table 1 reports results of covariance analysis.

Treatment effect within the experimental group. Results of ANOVA, comparing the experimental groups' mean difference between pretest and posttest scores of both high and low achievers revealed the following: a) in reading comprehension, the mean difference between pretest and posttest scores of low achievers is not significantly different than the mean difference between pretest and posttest scores of the high achievers; b) in math word problem solving, the mean difference between pretest and posttest scores of low achievers is significantly different than the mean difference between pretest and posttest scores of the high achievers in favor of the low achievers; and c) in colored progressive matrices, the mean difference between pretest and posttest scores of low achievers is not significantly different than the mean difference between pretest and posttest scores of high achievers. Table 2 reports computed mean difference between pretest and posttest scores, standard deviations, and standard error of deviation on reading comprehension questions, math word problem solving questions, and colored progressive matrices. Table 3 reports source, degrees of freedom, mean square, and $\mathrm{F}$ ratios on the tests for low and high achievers in the experimental group.

Table 2 MD, SD, \& SE on Reading Comprehension (RC), Math Word Problem Solving

(MWP), and Colored Progressive Matrices (CPM) for the Experimental group

\begin{tabular}{llllllll}
\hline & \multicolumn{3}{l}{ Low Achieving } & \multicolumn{3}{l}{ High Achieving } \\
& $n=10$ & & & & $n=15$ \\
\cline { 2 - 3 } \cline { 6 - 8 } & $M D$ & $S D$ & $S E$ & & $M D$ & $S D$ & $S E$ \\
\hline RC & 3.47 & 19.57 & 5.11 & & 5.01 & 13.45 & 4.16 \\
MWP & 22.0 & 18.74 & 4.93 & & 8.0 & 13.2 & 4.03 \\
CPM & 4.44 & 4.78 & 1.38 & & 2.78 & 4.39 & 1.12 \\
\hline
\end{tabular}

Table 3 Results of ANOVA for Low and High Achievers in the Experimental Group

\begin{tabular}{llll}
\hline & $M S$ & $d f$ & $F$ \\
\hline RC & 15.77 & 1 & 0.06 \\
MWP & 1176.0 & 1 & $0.04 *$ \\
$C P M$ & 16.68 & 1 & 0.88 \\
\hline
\end{tabular}

Qualitative data. All along the training, students showed high level of motivation. This was evidenced by students' interaction with the trainer in the introductory session as they stated possible examples of situations that 
require problem solving. Students' motivation was also evidenced by time on task and persistence to build a bulletin board for problem solving theme. As the training proceeded, students continued demonstrating a high level of motivation and by the end of the first week, Grade 5 homeroom teacher reported that students were reminding each other to use PKA while working on science tasks.

Close observation during the second week of training showed that Grade 5 students attempted to use the two strategies that they were exposed to. Most Grade 4 students continued to use the initial strategy (PKA) that they were exposed to. With some prompts, they attempted using CM as well to complete given tasks. Homeroom teacher for Grade 5 reported that several students were representing information given during other classes in a form of sketches and drawings. They explained to her that they were concept mapping. During the third week, and after introducing TA, it was observed that most students in Grades 4 and 5 relied more on using PKA and TA at the initiation of tackling given problems and towards the end of solving the task. CM was the least strategy used independently by students in Grade 4. Those who attempted using it soon dropped its use unless they received some kind of guidance, either from the trainer or from their peers.

In an unstructured conversation with homeroom teachers 4-weeks after post testing was over, homeroom teachers agreed that their students still used PKA and TA during regular classes, though inconsistently.

\section{Discussion}

The purpose of the study was, first, to investigate the effect of training in PKA, CM, and TA on problem solving performance within the contexts of reading comprehension and math word problem solving, and on content free problem solving tasks. Second, the study aimed at determining whether training in PKA, CM, and TA will have a different effect on the problem solving performance of low and high achieving students. The results of the study indicated that there was a significant difference between the experimental and the control groups' posttest scores on the three measures: (a) reading comprehension posttest scores, (b) math word problem solving posttest scores, and (c) CPM posttest scores. Results also revealed a significant difference in the mean difference of pretest and posttest scores between low and high achieving students within the experimental group on math word problem solving questions only.

Effect of training on posttest scores. Several factors may have contributed to the significant difference in posttest scores of experimental and control groups on criterion measures. It can be attributed to the quality of the training conducted, the training method used, and to both. Moreover, the nature of the tasks may have also played a role in producing significant differences. 
Quality of training. The quality of the training may have played a role in affecting the results since it includes strategies that promote metacognition and involves a combination of strategies which encompass the stages of the problem solving process.

With PKA, subjects oriented themselves to the problem solving process by examining the characteristics of the task and inspecting their prior knowledge for related tasks. With CM, subjects got actively engaged in representing problems and the interrelationships among elements of problems, such that they could identify cues to solve problems. With TA, subjects monitored their performance as they took a series of decisions on how to approach the problem solving task. In other words, while applying the strategies, subjects demonstrated basic metacognitive behaviors including (a) connecting new information to previous one, (b) selecting thinking strategies, deliberately, and (c) planning, monitoring, and evaluating thinking processes (Blakely \& Spence, 1990). While PKA ensured that students connected new information to previous ones, CM and TA guaranteed planning, selecting, monitoring, and evaluating of the thinking processes. Hence, it is possible that the training offered students a set of guidelines that provide a general direction to solve problems. Findings in educational psychology show that competent students and expert problem solvers have general metacognitive knowledge and skills (Masui \& DeCorte, 1999). Moreover, guidance and practice in applying metacognitive strategy helps individuals successfully solve problems throughout their lives (Mayer, 1998; Palincsar \& Klenk, 1992; Teong, 2003).

An additional power of metacognitive strategies lies in the motivational role that they play as they act as enabling skills which empower students to regulate learning (Masui \& DeCorte, 1999; Swanson \& De La Paz, 1998). As it is impossible to isolate the cognitive from the affective domain, metacognitive strategies are recommended by brain-based education.

Taken separately, each strategy, PKA, CM, and TA, has been formally evaluated and found to be effective in improving student learning (Dole, Brown \& Trathen, 1996; Gaith, 2001; Guastello, 2000). In this study, it was observed during the training that once students were exposed to more than one strategy, they combined strategies and used them to solve problems. The combination of the strategies together could have helped students be strategic while moving through different stages of the problem solving process. Results from studies that examine the effect of multiple strategies or packages of strategies on student learning augment findings from studies that examine a single strategy effect (Barkowski, Weyhing, \& Cart, 1988; Graves, 1986; Malone \& Mastropieri, 1992; Schmidt, Rozendal, \& Greenman, 2002). DeCorte, Verschaffel, and DeVen (2001) reported gains in students' reading comprehension following the implementation of comprehension strategy and metacognitive strategy training, with evidence of transfer. The combination of 
training components was assumed to be responsible for the gains. In the area of mathematics, Montague (as cited in Montague 1997), suggested that the combination of cognitive and metacognitive components of instruction was more effective to improve math performance than either cognitive or metacognitive strategy taught in isolation. Montague, Applegate, and Marquard (1993) also indicated that a combination of cognitive and metacognitive strategy instruction is an optimal learning package in improving students' math word problem in terms of rapid progress and maintenance of progress. In the current study, the combination of strategies used may have affected the results, especially that the three strategies tackle all stages of the problem solving process.

Training method. Previous studies have showed that increases in learning followed explicit instruction in metacognitive strategies, allowing initial practice using the strategies during group-based activities, then practice on an individual basis to gradually enhance independent use of strategies (Mastropieri, Scruggs, \& Graetz, 2003). In the current study, the teaching method followed in the training of the strategies entailed (a) explicit description of the strategy, what it accomplishes, when and where it may be used, (b) modeling strategy use to demonstrate the process and how to manage some intricacies, and (c) guided practice during group- based activities then on an individual basis to provide several practice opportunities allowing gradual shift in responsibility from teacher to student. Corrective feedback was given all along and peer correction was made use of. Research on metacognitive instruction in the domain of reading demonstrates a moderately strong relation between awareness of strategies, the use of strategies, and reading comprehension when the instructional method follows direct instruction, modeling, guided practice, and independent application (Cross \& Paris, 1988). Swanson (1989) describes the steps as a self-regulatory model for strategy development. Swanson and De La paz (1998) point out that a selfregulatory model for teaching strategies is especially useful for training strategies to students with and without learning difficulties in several academic contents.

From the brain-based learning perspective, a method that allows for the presence of a model, constructive feedback, low levels of threat, as well as peer mediated learning is highly recommended. With the model role-playing the use of strategies, at least two modes of input are ensured, visual and auditory. An alternate form of learning is also provided by peer mediated learning through group work and peer correction activities. Research conducted by Lockwood and Kunda (1999) indicated that the brain responds well to the influence of positive role models, especially if these relationships are interactive and include regular intervals of feedback. When constructive feedback is provided, feelings of threat and uncertainty are reduced and 
learners exhibit better coping skills (Jensen \& Dabney, 2001).

Nature of the tasks. The tasks that were developed and used while training in strategies may have also impacted the results. The reading selections were at the students' reading level, printed in a reader friendly fashion with paragraphs being short rather than being densely worded. The selections contain an acceptable number of new vocabulary words and are highly motivating as the majority present novel information regarding a variety of topics. From the brain-based perspective, these selections represent stimulating and enriching experiences that guaranteed students' attention as they triggered their emotions. The math tasks represented word problems that correspond to real-life experiences and present meaningful examples of math concepts. They were selected and adapted to invoke students' motivation. Brain-based learning asserts that tasks must be designed and orchestrated to provided experiences that are enriching, meaningful, and as close to real-life experiences as much as possible.

It is concluded that the set-up of the study, including strategies, teaching method, and tasks used had an effect on the results obtained. The factors involved in the training, quality of strategies, training method, and nature of tasks, provide an environment, that brain-based learning advocates.

Differential Effect of Training on Low and High Achievers. While significant differences were obtained for low and high achievers on math word problem solving performance following the training, insignificant differences were noted for reading comprehension and content free problem solving task performance.

Math word problem solving. The significant difference obtained in the results comparing the gains of low versus high achievers is consistent with research findings reported in the literature (Montague, 1997). Results of this study are also consistent with findings of Owen and Fuchs (2002) indicating that metacognitive strategy training produced positive effects on math word problems among third graders with learning difficulties and low achievement.

Reading comprehension. The lack of significant difference between the low and high achieving experimental groups' scores on reading comprehension questions is inconsistent with findings of researchers that recommend the use of metacognitive strategy instruction to improve reading comprehension performance of students who have learning difficulties (Palincsar \& Brown as cited in Gage \& Berliner, 1998). Although instruction including metacognitive skills training is believed to be a key to remediation of a reading problem and consequently to successful inclusion (Dole et al., Englert et al., Pressley et al., as cited in Schmidt et al., 2002), Schmidt et al. found a very limited number of empirical studies that examined reading strategy instruction, specifically in inclusive elementary classes. 
Three studies that match the conditions of the current study were cited as they were implemented in inclusive classrooms and targeted reading comprehension through metacognitive strategies. However, the strategies trained were different and the implementation period of the training was longer. In inclusive classrooms which are composed of diverse learners, intensive instruction and ample practice to implement a strategy that requires independent thinking or insight on the part of the student may be required. Components of direct instruction approach including redundancy and careful task sequencing may also be needed (Mastropieri \& Scruggs, 1997) as well as a great deal of supervised feedback (Swanson, 1989). Such components are not applied as often in an inclusive classroom. Given that the training in the current study was conducted in an inclusive classroom, low achievers and students with learning difficulties may not have had sufficient instruction, practice, feedback, or time for becoming proficient in using the strategies. The low achieving group received similar instruction, same amount of practice opportunities, and similar feedback instances as the high achieving group.

Impact on CPM. Lack of significant difference between the low and high achieving experimental groups' scores on CPM can be explained in terms of the absence of strategy transfer to complete CPM. Transfer of the taught strategies to complete the CPM tasks required (a) decontextualization of the strategies from the academic contexts in which the strategies were taught and (b) application to matrices, thus showing evidence of general transfer. Owen and Fuchs (2002) have reported that general transfer did not spontaneously occur in experimental groups of students with learning disability who received strategy instruction; rather it occurred in the experimental group that received full instruction in strategy acquisition plus explicit instruction in transfer of strategy. It was concluded that (a) transfer was not promoted by learning disabled students to situations that differed from those in which students were originally trained and (b) explicit instruction in strategy transfer is required. To enhance general transfer, students need to be explicitly taught to generalize strategy use (Snowman \& Biehler, 2003; Swanson \& De LaPaz, 1998). Furthermore, learners need to be frequently provided with a wide variety of transfer tasks. Wong (as cited in Schmidt et al., 2002) suggested several instructional parameters to promote transfer of learned strategies by students with learning difficulties, including (a) scheduling programmed practice with transfer tasks, and (b) asking students to verbalize the rationale for selecting and using particular strategies during transfer. In the current study, these conditions were not met. Students were not explicitly trained to decontextualize the strategies from the academic context and then apply them to solve content free tasks. In our study, although a change has occurred, this change was the same for both low and high achievers. Factors attributing to this finding in CPM are the fact that the duration of the training was not long 
enough to impact transfer, and the small sample sizes of each of the low and high achieving students within the experimental group.

Moreover, in this study, problem solving performance of content free tasks was measured by CPM which imposes some limitations on the measurement of the problem solving performance of diverse learners in an inclusive classroom. CPM does not fully account for the emotional and motivational components of the problem solving process, despite the fact that the matrices are printed with colored backgrounds (Raven, Raven \& Court, 1991). CPM poses problems that are not tailored to the values of those who are being assessed. Rather, it assesses problem solving behaviors in relation to tasks set forth by test constructors, which might render demotivated test takers, particularly among low achieving students and students with learning difficulties. As a result, low achievers might not have showed their full potential on the CPM measure. For more accurate information, Raven recommended that $\mathrm{CPM}$ is to be accompanied by other qualitative measures that help discover how test takers perceive the problems and what strategies were involved in the completion of the matrices. A second limitation of the CPM lies in the fact that the tasks are based on the presentation of geometric figures. Students with perceptual processing, visual-spatial, or sequencing difficulties may have difficulties to initially perceive the tasks presented in the matrices (Mills \& Ablard, 1993). Consequently, low scores on the CPM might be a function of perceptual difficulties rather than problem solving deficiency.

In conclusion, the lack of explicit training to transfer strategies, the short duration of the training, the small sample size, and the use of CPM tool may have contributed to the insignificant changes on the CPM between low and high achievers.

Qualitative results. The researcher's qualitative observations and feedback from homeroom teachers were significant because they highlighted certain aspects in the research that were not addressed such as students' motivation, strategy maintenance over time, and strategy generalization to contexts other than the training ones. A high level of involvement and motivation among students was especially significant, knowing that high levels of achievement and high levels of motivation tend to positively correlate (Gage \& Berliner, 1998). Students' combination of strategies taught was particularly significant as it reflects flexibility in thinking indicating that learners are involved in self-regulatory processes during problem solving. Homeroom teachers' feedback was also significant as it highlighted that some learners retained the strategies taught and applied them after some time has passed. Moreover, it highlighted that some students attempted to generalize the strategies to contexts other than the training situations. 


\section{Limitations}

The sample size being small poses a limitation to the study. This is especially important to be noted with regards to findings concerning the generalizability of findings relevant to the treatment effect within the experimental group. The two groups (low and high achieving groups in the experimental sample) which were compared using ANOVA consisted of a small sample size. The non-significant results obtained between high and low achieving groups on reading comprehension and CPM may be attributed to the small sample. The same may be true for the finding that favored low achievers on math word problem solving

\section{Implications and Recommendations}

The major implication of this study indicates that implementing PKA, $\mathrm{CM}$, and TA enhances students' problem solving performance within an academic context as well as on content free problem solving tasks. Another implication is that low achievers do improve their mathematical problem solving performance under conditions such as those described in this study. On the basis of the results obtained, explicit instruction of strategies, modeling, guided learning experiences, and corrective feedback seem to enhance strategy acquisition and application in math problem solving tasks among low achieving students. While this study revealed promising results pertaining to the impact of implementing PKA, CM, and TA on students' learning, continued research in this area is crucial for further validating these and other brain-compatible strategies to enhance and reinforce problem solving performance. Further research should aim at studying the effect of brain compatible strategies on the problem solving with follow up and monitoring of strategy implementation to directly report and detect desirable changes. Further research is also needed on the differential effect of the factors that contributed to the results such as selected strategies, training method, and nature of tasks; and it also could include the identification of other variables that might have affected the results such as students' attitude.

\section{References:}

1. Abbeduto, L. (2004). Taking sides: Clashing views on controversial issues in educational psychology ( $3^{\text {rd }}$ ed). Connecticut: McGrawHill/Dushkin.

2. Barkowski, M., Weyhing, R. S., \& Cart, M. (1988). Effects of attributional retraining on strategy based reading comprehension in learning disabled students. Journal of Educational Psychology, 80, 4653.

3. Bello, D. M. (2007). The effect of brain-based learning with teacher training in division and fractions in fifth grade students of a private 
school (Order No. 3274980). Available from ProQuest Dissertations \& Theses Global. (304721280). Retrieved from https://searchproquestcom.ezproxy.aub.edu.lb/docview /304721280? accountid $=8555$

4. Blakely, E. \& Spence, S. (1990). Developing metacognition. (ERIC Document Reproduction Service No. ED 327218)

5. Brodnax, R. M. (2004). Brain compatible teaching for learning. (Unpublished doctoral dissertation). Indiana University, Indiana.

6. Caine, G. \& Caine, R. N. (1995). Reinventing schools through brain based learning. Educational Leadership, 52, 43-47.

7. Cross, D. R. \& Paris, S. G. (1988). Developmental and instructional analyses of children's metacognition and reading comprehension. Journal of Educational Psychology, 89, 131-142.

8. DeCorte, E., Verschaffel, L. \& DeVen, A. (2001). Improving text comprehension strategies in upper primary school children: A design experiment. British Journal of Educational Psychology, 71, 531-559.

9. Dole, J. A., Brown, K., \& Trathen, W. (1996). The effect of strategy instruction on the comprehension performance of at-risk students. Reading Research Quarterly, 31, 62-85.

10. Duman, B. (2010). The effects of brain-based learning on the academic achievement of students with different learning styles. Educational Sciences: Theory \& Practice, 10(4), 2077-2103

11. El Daw, B. (1997). The effect of language-related concepts training and verbal instruction on self-regulated problem solving in mild mentally retarded students: A follow up study. (Unpublished Project) American University of Beirut, Lebanon.

12. El-Hassan, K. \& Moughanie, Z. (2013). Implementation of the social decision-making skills curriculum on primary students (Grades 1-3) in Lebanon. School Psychology International, 35(2), 167-175. doi: 10.1177/0143034312469758

13. Englert, C. S., Raphael, T. E., Anderson, L. M. Anthony, H. M., \& Stevens, D. (1991). Making strategies and self-talk visible: Writing instruction in regular and special education classroom. American Educational Research Journal, 28, 337-372.

14. Fogarty, R. (2009). Brain-Compatible Classrooms (3rd ed.). Thousand Oaks, Calif: Corwin

15. Gage, N. L. \& Berliner, D. C. (1998). Educational Psychology (6th ed.). Boston: Houghton Mifflin.

16. Gaith, G. (2001). Effect of think alouds on literal and higher order reading comprehension. Educational Research Quarterly, 26, 13-21. 
17. Graves, A. (1986). Effects of direct instruction and metacomprehension training on finding main ideas. Learning Disabilities Research, 1, 90-100.

18. Guastello, E. F. (2000). Concept mapping effects on science content comprehension of low achieving inner city seventh graders. Remedial and Special Education, 21, 356-364.

19. Haghighi, M. (2013). The effect of brain- based learning on Iranian EFL achievement and retention. Procedia Social and Behavioral Sciences, 70, 508 - 516. doi: 10.1016/j.sbspro.2013.01.088

20. Jensen, E. (1998). Teaching with the brain in mind. Alexandria, VA: Association for Supervision and Curriculum Development.

21. Jensen, E. (2008). A fresh look at brain-based education. Phi Delta Kappan, 89, 408-417.

22. Jensen, E. \& Dabney, M. (2001). Learning smarter: The new science of teaching. Alexandria, VA: Association for Supervision and Curriculum Development.

23. Lockwood, P. \& Kunda, Z. (1999). Increasing the salience of one's best selves can undermine inspiration by outstanding role models. Journal of Personality and Social Psychology, 76, 214-228.

24. Malone, L., D. \& Mastropieri, M. A. (1992). Reading comprehension instruction: Summarization and self-monitoring training for students with learning disabilities. Exceptional Children, 58, 270-279.

25. Mastropieri, M. A. \& Scruggs, T. E. (1997). Best practices in promoting reading comprehension in students with learning disabilities. Remedial and Special Education, 18, 197-216.

26. Mastropieri, M. A., Scruggs, T. E. \& Graetz, J. E. (2003) Reading comprehension instruction: Challenges for secondary struggling students and teachers. Learning Disability Quarterly, 26, 103-116.

27. Masui, C. \& DeCorte, E. (1999). Enhancing learning and problem solving skills: Orienting and self-judging, two powerful and trainable learning tools. Learning and Instruction, 9, 517-542.

28. Mayer, R. E. (1998). Cognitive, metacognitive, and motivational aspects of problem solving. Instructional Science, 26, 49-63.

29. McCormick, C. B., Miller, G., \& Pressley, M. (1989). Cognitive strategy research: From basic research to educational applications. NewYork: Springer-Verlag.

30. Mills, C. J. \& Ablard, K. E. (1993). The Raven's Progressive Matrices: Its usefulness for identifying gifted and talented students. Roeper Review, 15, 183-186.

31. Montague, M. (1997). Cognitive strategy instruction in mathematics for students with learning disabilities. Journal of Learning Disabilities, 30, 164-177. 
32. Montague, M., Applegate, B., \& Marquard, K. (1993) Cognitive strategy instruction and mathematical problem solving performance of students with learning disabilities. Learning Disabilities Research and Practice, 8, 223-232.

33. Montague, M., Krawec, C. Enders, S. and Dietz, S. (2014). The effects of cognitive strategy instruction on math problem solving of middleschool students of varying ability. Journal of Educational Psychology, 106 (2), 469-481. doi. 10.1037/a0035176

34. Nashabi, R. (1998). The effect of the ACCEPTS social skills training on social interaction between regular and special students in an integrated setting. (Unpublished thesis). American University of Beirut, Lebanon.

35. Owen, R. L. \& Fuchs, L. S. (2002). Mathematics problem solving strategy instruction for third grade students with learning disability. Remedial and Special Education, 23, 268-278.

36. Palincsar, A. S. \& Klenk, L. (1992). Fostering literacy learning in supportive contexts. Journal of Learning Disabilities, 25, 211-225.

37. Phye, G. D. (2001). Problem solving instruction and problem solving transfer: The correspondence issue. Journal of Educational Psychology, 93, 571-578.

38. Pressley, M., ElDinary, P. B., Gaskins, I., Schuder, T., Bergman, J. L., Almasi, J., \& Brown, R. (1992). Beyond direct explanation: Transactional instruction of reading comprehension strategies. Elementary School Journal, 92, 513-555.

39. Pressley, M., \& Harris, K. (2008). Cognitive strategies instruction: From basic research to classroom instruction. The Journal of Education, 189, 77-94.

40. Raven , J. C., \& Raven, J. H., \& Court, J. H. (1991). Raven Manual: General overview._(4th ed.) England: Oxford Psychologists Press.

41. Schmidt, R. J., Rozendal, M. S.; \& Greenman, G. G. (2002). Reading instruction in the inclusion classroom. Remedial and Special Education, 23, 130-140.

42. Snowman, J. \& Biehler, R. F. (2003). Psychology applied to teaching (10th ed.). Boston: Houghton Mifflin.

43. Sternberg, R. (2008). The answer depends on the question: A reply to Eric Jensen. Phi Delta Kappan, 89, 418-420.

44. Suarsana, M., Widiasih, S. \& Suparta, N. (2017). The effect of brain based learning on second grade junior students' mathematics conceptual understanding of polyhedron. Journal on Mathematics Education, 9 , 145-156.

doi: 10.22342/jme.9.1.5005. 
45. Swanson, H. L. (1989). Strategy instruction: Overview of principles and procedures for effective use. Learning Disability Quarterly, 12, 314.

46. Swanson, H. L. \& De La Paz, S. (1998). Teaching effective comprehension strategies to students with learning and reading disabilities. Intervention in Schools and Clinic, 33, 209-218.

47. Swanson, H. L. \& Hoskyn, M. (1998). Experimental intervention research on students with learning disabilities: A meta-analysis of treatment outcomes. Review of Educational Research, 68, 277-321.

48. Teong, S. K, (2003). The effect of metacognitive training on mathematical word problem solving. Journal of Assisted Learning, 19, 46-55.

49. Tüfekçia, S., \& Demirel, M. (2009). The effect of brain based learning on achievement, retention, attitude and learning process. Procedia Social and Behavioral Sciences, 1, 1782-1791. doi:10.1016/j.sbspro.2009.01.316

50. Wilder, A. \& Williams, J. (2001). Students with severe learning disabilities can learn higher order comprehension skills. Journal of Educational Psychology, 93, 268-278.

51. Winters, C. A. (2001). Brain based teaching: Fad or promising teaching method. (ERIC Document Reproduction Service No. ED 455218)

52. Wolfe, P. (2001). Brain matters: Translating Research into classroom practices. Alexandria, VA: Association for Supervision and Curriculum Development.

53. Wong, B. Y. L, Harris, K. R., Graham, S., \& Butler, D. L. (2003). Cognitive strategies instruction research in learning disabilities. In $\mathrm{H}$. L. Swanson, K. R. Harris, \& S. Graham (Eds.), Handbook of learning disabilities (pp. 383-402). New York: Guilford Press.

54. Youness, J., \& AbdelFattah, Kh. (2015). The Effectiveness of a brainbased teaching model on the acquisition of physical concepts and the development of attitudes towards Physics and maintaining the effect of learning of 1st year high school students. Journal of Arabic Studies in Education and Psychology, 67, 17-62. doi: 10.12816/0022632 